\title{
Current Quality Management Practices In U.S. Hospitals: A Survey
}

Jayanta K. Bandyopadhyay, Central Michigan University, USA

\begin{abstract}
For decades, the U.S. health care industry has been operating on its own, ignoring emerging factors, such as competition, patient safety, skyrocketing health care cost, liability, malpractice insurance cost, and DRG for Medicare payment. However, as these factors became more prevalent and competition within the industry intensified, many U.S. hospitals have been becoming increasingly aware of the critical needs of controlling the operating costs and attempting to meet the needs and expectations of patient care quality. This paper presents the findings of a questionnaire survey unveiling the current quality management policies and practices in U.S. hospitals for achieving excellence in patient care quality.
\end{abstract}

\section{INTRODUCTION}

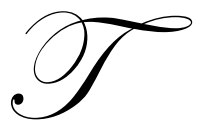

he health care industry in the U.S has been operating on its own traditional economic domain ignoring current emerging factors such as competition, patient safety, skyrocketing health care cost, liability from malpractice lawsuits and government control on Medicare payment (Hansson, 2000). As these factors became more prevalent and competition within the industry has been intensified in recent years, many U.S. hospitals have been becoming increasingly aware of the critical needs of controlling their operating costs and meeting the expectations of patient care quality (Chow-Chua et.al, 2000). In the current competitive environment, many health care organizations are taking steps to ensure that they are providing the "absolute best care at the lowest possible costs". However, many hospital administrators still have to learn how to lower operating costs without compromising on providing consistent good quality patient care (Griffith, 2000).

In 1993, Chaufournier et al. reported that $44 \%$ of 1,083 hospitals surveyed in the U.S. were embracing some kind of quality management approach, such as CQI (Continuous quality improvement), Kaizen, and TQM (Total Quality Management) to improve health care quality (2). Also in 1994, Hertz, et al suggested that Malcolm Baldridge National Quality Award (MBNQA) concepts could help stimulate health care quality improvement (11). In 2001, Leggit, and Anderson reported that the Malcolm Baldrige National Quality Award (MBNQA) assessment criteria for Performance Excellence, developed by National Institute of Standards and Technology, has been successfully applied for organization-wide performance improvement at Hartford Hospital at Hartford, Connecticut (13).

Cho-Chua, et al (2002) affirms that the health care delivery system has been undergoing formidable challenges since the early 1990s due to many formidable forces, such as increased customer expectations, steeper competition, and government agency pressures (4). Therefore, in order to meet the challenge of the current environment, some of the U.S hospitals have already started using a number of quality and productivity management tools and techniques that have been proven successfully in many organizations in the manufacturing and service industries.

\section{QUALITY AND PRODUCTIVITY MANAGEMENT TOOLS AND TECHNIQUES}

The following quality and productivity management tools and techniques are widely and successfully used by many organizations in manufacturing, as well as in service industries, and are currently being tried in health care industries. 
- $\quad$ Statistical Quality Control (SQC)

- $\quad$ Total Quality Management (TQM)

- $\quad$ ISO-9000 Series of quality standards

- $\quad$ Malcom Baldrige National Quality Award Criteria

- $\quad$ Six Sigma Quality improvement approach

\section{Statistical Quality Control (SQC)}

Statistical quality control chart was first introduced by Walter Shewart and Harold Dodge in the U.S. in early 1950s. Edward W. Deming, who is considered as the father of quality management, was the first to introduce the SQC techniques using SQC charts in the manufacturing industry in the early 1960s as the most effective and efficient way to control manufacturing quality. Since then, SQC has been extensively used in the manufacturing industry for effectively and efficiently controlling quality of manufactured products. SQC has also been used successfully for controlling the quality in a number of service industries, such as fast food, restaurant, banking and telephone. However, irrespective of its potential use, there are very few evidences of successful use of SQC in the health care industry.

\section{Total Quality Management (TQM)}

A.V. Feigenbaum first recognized the importance of a comprehensive approach to quality and coined the term "total quality control". Feigenbaum emphasized that the quality of a product or service is directly influenced by what he termed the 9Ms: markets, money, management, men and women, motivation, materials, machines and mechanization, modern information technology, and mounting product/service requirements (7). The core principles of TQM are: focus on customers, employees' participation and team work, continuous improvement, and learning. TQM has been widely introduced and accepted in the manufacturing and service industries, including health care. In fact, the foundation of ISO-9000 core requirements and MBNQA criteria are developed upon TQM principles (7).

\section{ISO-9000 Series of Quality Standards}

The ISO-9000 series of quality standards was developed by International Standard Organization in the 1990s by harmonizing all kinds of quality standards developed all over the world. It uses a TQM approach to a production/service system, proposing that only a good quality production/service system can produce good quality products or offer good quality services. The ISO-9000 series of standards involves 20 core requirements for determining a good quality system and it has been extensively adopted in the manufacturing industry all over the world, particularly for supplier's certification. ISO-9000 certification has also been adopted by many serviceoriented companies for receiving recognition as "high quality" service companies. However, very few hospitals or health care providers are currently ISO-9000 certified or sought such certification.

\section{Malcom Baldrige National Quality Award}

In 1985, the Malcom Baldrige National Quality Award (MBNQA) was introduced during President Reagan's administration as an act of Congress to recognize the organizations offering the highest quality products and services. The three categories in which an organization has been recognized each year since 1988, using a rigorous examination/quality auditing process by a panel of judges, are manufacturing, service, and small business. There are seven criteria used in determining the Malcom Baldridge award winners: 1) leadership, 2) strategic planning, 3) customer and market focus, 4) information and analysis, 5) human resource focus, 6) process management, and 7) business results. All seven criteria totals a maximum possible score of 1,000 points, while the seventh criteria (the business results, which includes customers' satisfaction, financial and market, human resources, suppliers' and partners', and company specific) amounts to a total of 450 points. Many companies are using this award criteria to evaluate their own quality programs and implement quality initiatives (7). 


\section{Six Sigma Approach to Quality Management}

The Six Sigma approach to quality management has evolved from a simple quality management framework to an overall strategy to accelerate improvements and achieve unprecedented performance levels by focusing on characteristics that are critical to customers/patients by identifying and eliminating causes of errors or defects in the care-giving process. A six sigma quality level represents at most 3.4 errors per million opportunities and corresponds to a process variation equal to half of the design tolerances, while allowing the process mean to shift as much as 1.5 standard deviation from the target (10). Originally developed by Motorola Corp. for use in manufacturing in the context of tolerance-based specifications, Six Sigma has been applied to product development, customers' services, accounting, and many other business functions in manufacturing, as well as service industries. For achieving the Six sigma quality level, Six Sigma uses the DMAIC (Define, Measure, Analyze, Improve and Control) problem-solving methodology. Six Sigma recognizes that an error occurs due to a quality problem; therefore, the error can be eliminated by defining the problem, finding the magnitude and the root cause of the problem by measuring and analyzing the data, and improve by permanently removing the cause of the problem and setting up a control system for preventing any such problems to reoccur.

\section{CURRENT QUALITY MANAGEMENT PRACTICES IN MICHIGAN HOSPITALS}

A questionnaire survey was mailed to 100 hospitals randomly selected from the Membership Directory of American Hospital Association (AHA) in order to explore their current quality management policies and practices. The response rate was 30 percent, which is very common and reasonable for a mail questionnaire survey in the U.S. Data collected from the questionnaire were coded and analyzed for meaningful factual information.

\section{Current Quality Management Practices in American Hospitals} information:

The analysis of the factual data from the questionnaire revealed the following surprising factual

- 90 Percent of the hospitals that responded to the survey reported that they are accredited by Joint Commission on American Hospital Organization (JCAHO) and/or some other agency.

- $\quad 90$ Percent of the hospitals that responded to the survey reported that they have a strategic plan with a focus on quality.

- 80 Percent of the hospitals who responded to the survey reported that they have a quality policy manual.

- 80 Percent of the hospitals that responded to the survey reported that they have quality procedures.

- 80 Percent of the hospitals that responded to the survey reported that they have developed some quality standards for auditing some of their critical departments.

- $\quad 80$ Percent of the hospitals that responded to the survey reported that they keep records of standard treatment procedures.

- 85 Percent of the hospitals that responded to the survey reported that they have a quality assurance department and that they have at least one internal quality auditor.

- 85 Percent of the hospitals that responded to the survey reported that they have at least one quality manager.

- $\quad 90$ Percent of the hospitals that responded to the survey reported that they have embraced, for customers' safety and satisfaction, a Total Quality Management (TQM) approach which encourages continuous improvement.

- $\quad 90$ Percent of the hospitals that responded to the survey reported that they regularly run a customer satisfaction survey and analyze the factual information for prompt corrective actions.

- $\quad$ Only 10 percent the hospitals that responded to the survey reported that they have applied for Malcom Baldridge National Quality Award (MBNQA) and/or ISO9002 Certification. 


\section{DISCUSSION OF THE RESULTS LIMITATIONS}

- $\quad$ This has been an exploratory research to find factual information regarding the current quality management policies and practices in U.S. hospitals. Because of the limitation of the resources, the mail survey was limited to 100 hospital administrators randomly selected from the Directory of American Hospital Association (AHA). The response rate was 30 percent, which is very reasonable for a mail survey in the U.S.

- $\quad 90$ Percent of the hospitals that responded to the survey reported that they are accredited by Joint Commission on American Hospital Organization (JCAHO) and/or some other agency. As part of the accreditation requirements, they have a quality focus on their strategic plan and top management commitment to quality. They also have a well documented quality policy, quality procedures, and quality instructions. They maintain their treatment records, laboratory, and equipment calibration records. They regularly run customer satisfaction surveys and analyze the factual information for prompt corrective actions.

- None of the hospitals reported that they have developed or established a quality standard for quality audit of their department or procedures.

- $\quad$ Also, none of the hospitals reported that they are using SQC for patient care quality monitoring and control or SPC of the treatment processes and procedures.

- Also, none of the hospitals reported that they use the Six Sigma approach to quality problem-solving in any of their departments.

\section{CONCLUSION}

Many U.S. hospitals are striving to improve their productivity and cost effectiveness by continuously upgrading their equipment through lease/purchase and improving their nursing, patient/insurance billing and other services through rigorous training, outsourcing, and using state of the art information technology. But other than meeting the accreditation requirements of their accreditation authority, they are still operating in their own domain, ignoring the importance of improving patient care quality by not utilizing the available powerful quality management tools and techniques. The author strongly believes that all hospitals must take a proactive approach to improve their patient care quality, along with improving productivity and becoming a role model for all global health care systems.

\section{REFERENCES}

1. Branan K.M.(1997), "Total Quality in health care", Production and Inventory Management Journal, Vol. 38, No. 2, pp. 69-73.

2. Bandyopadhyay, Jayanta K., (2000), "ISO9000 Registration for achieving competitive edge in the world marketplace", International Journal of Management, London, U.K. March, pp. 65-69.

3. Bandyopadhyay, Jayanta K. (2001) "Quality systems requirements in supply chain quality management: The implementation of QS-9000 by U.S. automakers" International Journal of Management, London, U.K., June, pp. 101-105

4. Choufournier, R.L. and St. Andre C. (1993), "Total quality management in an academic health center", Quality Progress, April, pp 63-66.

5. Chow-Chua, F.P and Goh, M.(2000)," Quality roadmap of a restructured hospital", Managerial Audit Journal, Bradford, U.K., Vol. 15, No.2, pp. 29.

6. Chow-Chua, F.P and Goh, M.(2000), "Quality improvement in health care industry", International Journal of Health care Management, Vol. 43, No. 4, pp 223-229.

7. Chow-Chua, F.P and Goh, M.(2002)," A framework for evaluating performance and quality improvement in hospitals, Managing Service Quality, Vol.12, No.1, pp 54-66.

8. Crane, J.S. and Crane, N.K. (2000), "A multi-level performance appraisal tool: transition from traditional to CQI approach"', Health care Management Review, Vol.25, No.1, pp. 64-73.

9. $\quad$ Evans, James R. and Lindsay, William M., (2006) The Management and Control of Quality, South Western College Publishing, Cincinnati, Ohio, pp.137-140. 
10. Fleishman, R. (1996), " Evaluating intervention programs for quality assurance in hospitals", International Journal of Health Care Quality Assurance, Bradford, U.K., Vol.9, No.3, pp. 20-29.

11. Giffith, J.R., (2000) " Championship Management for health care organization", Journal of Health care Management, Vol 45, No.1, pp.17-31.

12. Hansson, J. (2000), "Quality in Health care: medical or managerial". Journal of Management in Medicine, Vol.14, No.5, pp. 356-361.

13. Hertz, H.S. , Reiman C.W., and Boswick, M.C. (1994)"The Malcolmn Baldridge National Quality Award concepts could help accelerate health care quality improvement", Quality Management in Health Care, Vol.2, No.4, pp. 63-72.

14. Lanser E.G. (2000), " Effective use of performance indicators" Healthcare Executive, September/October, pp.46-47.

15. Leggit, M.S. and Anderson, R. (2001). " Baldridge assessment strengthens competitive position for Hartford Hospital", Proceedings of 2001 ASQ Quality Congress, pp. 462-467.

16. McLauglin, C.P. (1998), "Evaluating the quality control system for managed care in the U.S", Quality Management in Health care, Vol. 7, No.1, pp. 38-40.

17. National Institute of Science and Technology (2001) website http:quality.nist.gov.

18. Panko, R. (1996), "The health care game: cutting cost but not quality" Best's Review (Life/Health), Vol.97, No. 4, pp. 32-36. 
NOTES 